\title{
How vulnerable are cetaceans to climate change? Developing and testing a new index
}

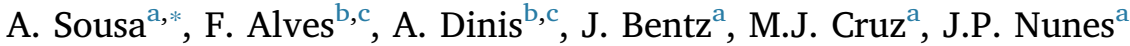

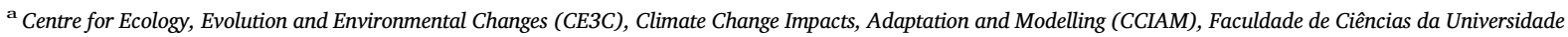 \\ de Lisboa, Campo Grande, 1749-016 Lisboa, Portugal \\ ${ }^{\mathrm{b}}$ CIIMAR-Madeira, Interdisciplinary Centre of Marine and Environmental Research of Madeira, Edifício Madeira Tecnopolo, Funchal, Portugal \\ ${ }^{\mathrm{c}}$ MARE, Marine and Environmental Sciences Centre/ARDITI, Madeira, Portugal
}

A R T I C L E IN F O

\section{Keywords:}

Climate change

Vulnerability assessment

Whales and dolphins

Northeast Atlantic

\begin{abstract}
A B S T R A C T
Climate change is altering chemical, physical and biological processes in the marine environment. Observed impacts driven by climate have been recorded and include changes in the geographical distribution, timing of seasonal migrations, breeding biology and behaviour of species. A number of qualitative and quantitative methodologies have been developed over the years to assess the vulnerability of animals to climate change. However, for marine species, the development and application of indices is recent, especially for large vertebrates such as marine mammals. In this context, the present study develops a trait-based climate change vulnerability index and applies it to seven cetacean species in the Madeira archipelago (Northeast Atlantic). The development of the index included the selection of sensitivity and exposure factors, the definition of each factor's score range, and the computation of results. It showed that the sperm whale (Physeter macrocephalus), the fin whale (Balaenoptera physalus), the Atlantic population of bottlenose dolphins (Tursiops truncatus) and the Bryde's whale (Balaenoptera brydei) were the most vulnerable species. The short-beaked common dolphin (Delphinus delphis), the island-associated bottlenose dolphins and the Atlantic spotted dolphin (Stenella frontalis) showed the lowest vulnerability to climate change. The outputs are consistent with previously proposed effects on whales and dolphins, considering their ecological similarities and exposure to environmental factors. This study shows that the developed index contributes to prioritize vulnerable species to climate change and to identify knowledge gaps in species ecological traits. The index results can contribute to inform policy makers in the definition of measures for species conservation.
\end{abstract}

\section{Introduction}

Marine ecosystems provide essential benefits to society through a number of regulatory, provisional, cultural and supporting services. These include food production for human consumption, cultural and recreational activities, the regulation of climate, and nutrient regeneration and supply (Millennium Ecosystem Assessment, 2005; Salomon and Dahms, 2018). However, oceans have been severely altered and depleted during the last century due to overfishing, chemical pollution, noise pollution or marine debris (Worm et al., 2006; Palumbi et al., 2009). In consequence, these services have been severely compromised, leading to the loss of biodiversity and their ecological functions (Duarte, 2000; Worm et al., 2006).

Climate change is causing an additional pressure to marine ecosystems increasingly threatened by these human induced pressures (Hoegh-Guldberg and Bruno, 2010). The effects of increased atmospheric greenhouse gas emissions leading to global warming, originates an increase in ocean heat content, ocean acidification, sea level rise and changes in current systems, contributing to the loss of marine biodiversity and ecosystem functions (IPCC, 2014; EEA, 2016) Observed climate impacts include changes in species geographical distribution, timing of seasonal migrations, breeding biology, and behavior (EEA, 2012; Brooker et al., 2007; EEA, 2016). Several studies have indicated that climate change, together with habitat loss or degradation resulting from human activities, heavily amplifies the vulnerability of species and ecosystems, constituting additional stress to biodiversity (EEA, 2012; Millennium Ecosystem Assessment, 2005; IPCC, 2014).

Several studies have described potential impacts of climate change on cetaceans (whales and dolphins), which are related to changes in the animals' distribution patterns, mainly due to variations in prey abundance or distribution (Learmonth et al., 2006; Simmonds and Isaac, 2007; Whitehead et al., 2008; Simmonds and Eliott, 2009; Simmonds,

\footnotetext{
* Corresponding author.

E-mail address: agsousa@fc.ul.pt (A. Sousa).
} 
2016). Changes in distribution may also lead to competition for resources among species (MacLeod, 2009). Besides these impacts, changes in length and timing of migrations (Ramp et al., 2015) and in reproductive success (Leaper et al., 2006) have also been found. Moreover, higher temperatures may increase susceptibility and incidence of diseases and decreased reproductive capacity (Aguilar and Raga, 1993; Simmonds and Mayer, 1997; Whitehead, 1997; Leaper et al., 2006; Gambaiani et al., 2009). Many cetaceans that have restricted geographic distributions such as arctic species are less likely to adapt to climate change (Kovacs and Lydersen, 2008; Laidre et al., 2008).

The vulnerability of species to climate change can be assessed through qualitative or quantitative analyses such as correlative, mechanistic, trait-based assessments or a combination of these approaches (Pacifici et al., 2015). The choice of the methodology will vary according to the objectives of the assessment and the temporal, spatial and taxonomic scales at which it takes place. The complexity of biological processes and interactions challenge a precise prediction of how species and biological systems will respond to these changes (Simmonds and Isaac, 2007; Cruz et al., 2015; Ramp et al., 2015; Silber et al., 2017). In particular, the difficulty to predict with high levels of certainty how biodiversity will respond to the various climate-induced changes such as habitat fragmentation, biotic interactions, and speciesspecific variation in migratory and evolutionary capacity is a major factor limiting the assessment of species vulnerability and the development and implementation of adaptation measures for species (Heller and Zavaleta, 2009; Bagne et al., 2011; Girvetz et al., 2014). Despite this, there is still a need to provide policy makers and conservation managers with tools for this purpose. Trait-based indexes are particularly useful for institutions planning to develop adaptation or conservation strategies with limited time and resources. In general, these indexes can evaluate a wide range of taxa, compare and rank vulnerability between species and identify the major factors of vulnerability and important knowledge gaps (Cruz et al., 2015; Young et al., 2015).

Challenges in the development of trait-based indices have been previously identified and focus on the selection and definition of sensitivity and exposure factors, namely: i) the potential co-relation between different factors (i.e. several factors measure the same aspect of vulnerability) (Simmonds and Smith, 2009), ii) unclear definition of factors which may lead to a biased application of the index by different experts (Simmonds and Smith, 2009; Lankford et al., 2014; Cruz et al., 2015), and iii) factors that may be relevant for some species but not for others (e.g. dependence on ice for some marine mammal species). Other identified limitations relate to the lack of information on specific parameters hindering their evaluation (Simmonds and Smith, 2009; Cruz et al., 2015). Possible impediments related to the computation of vulnerability scores include the weight attributed to different factors based on their relevance and the subjectivity involved in expert judgment scoring (Lankford et al., 2014; Cruz et al., 2015; Hare et al., 2016). In addition, a reduced number of experts can be a limitation to the robustness of vulnerability assessments. However, it can be difficult to recruit and involve experts with different backgrounds such as ecologists, oceanographers, climatologists or experts in the methodology development itself. Particularly in geographically isolated areas, gathering such expertise can be challenging. In the terrestrial environment, these challenges have been overcome and trait-based indexes have been used successfully to quantify species vulnerability to climate change (Davison et al., 2012; Gardali et al., 2012; Cruz et al., 2015). In the marine environment, the development and application of vulnerability indexes is more recent (e.g. Stortini et al., 2015; Hare et al., 2016), and, to our best knowledge, this is one of the first studies focusing on cetaceans.

The objective of this study was to develop a climate change vulnerability index for cetaceans' species and apply it in Madeira (Northeast Atlantic), an oceanic archipelago located in a warm-temperate latitude. It aimed at informing policy makers and identifying adaptation measures as a part of the archipelago's climate adaptation strategy. Our index follows the design developed by Hare et al. (2016) and accesses relevant factors that contribute to cetaceans' vulnerability. The advantages and limitations of this methodology are also considered. Finally, strategies for further improvement of the index in future vulnerability assessments are discussed.

\section{Methods}

\subsection{Index development approach}

The climate change vulnerability index for cetacean populations in the Madeira archipelago was constructed based on the selection of exposure and sensitivity factors relevant for cetacean species identified in Laidre et al. (2008) and Simmonds and Smith (2009). The assessment methodology was developed by Hare et al. (2016) for fishes and invertebrates to climate change in the NE U.S. Continental Shelf.

The index was developed in four steps:

1. In order to determine sensitivity factors relevant for cetacean species, a list of 16 potential factors was collected from two existing studies (Laidre et al., 2008; Simmonds and Smith, 2009). These factors were evaluated according to a set of criteria identified by Simmonds and Smith (2009): i) Data availability; ii) Objective definition; iii) Enabling differentiation, i.e. if the factor could contribute to differentiate vulnerability between species; and iv) No overlap, i.e. if the factor would measure a unique aspect of vulnerability and was not correlated with another listed factor. All factors that fulfilled these criteria were included in the index.

2. Exposure factors - sea surface temperature, salinity, $\mathrm{pH}$ and primary productivity - were obtained from NOAA's Earth System Research Laboratory (ESRL) online tool (http://www.esrl.noaa.gov/psd/ ipcc/). Historical climate data from 1956 to 2005 and climate projection anomalies for the RCP 8.5 scenario (2050-2099) (IPCC, 2014) for the NE ocean were considered for evaluation in the index (see supplementary material).

3. For each sensitivity and exposure factor, three categories were defined reflecting the factor's contribution to the vulnerability of cetacean species. This contribution ranged between low (1) and high (3).

Factors were scored following the method developed by Hare et al. (2016), which is based on expert evaluation and considers three category scoring bins for each factor; experts are assigned five tallies to be distributed in the three score bins. The attributed factors' scores are based on the scientific literature and general knowledge available. Thus, in the case of Hare et al. (2016), experts who were certain about a category of sensitivity or exposure scored all five tallies in one scoring bin, while experts who were less certain in scoring a factor could distribute their tallies in two or three scoring bins. Local cetacean experts were recruited for this case study (see below).

Scores were calculated by summing all factors' results and multiplying them by the respective category score (1,2 or 3 ). An average of the sensitivity and exposure scores was obtained. The vulnerability score was calculated as the product of sensitivity and exposure (Vulnerability $=$ sensitivity * exposure).

4. A confidence assessment was performed for each factor and for the overall vulnerability results. Confidence was assessed as the sum of the data quality score and the experts score distribution of each factor (Factors confidence $=$ experts distribution score + data quality). The experts score was measured through the experts' distribution of tallies in the different scoring bins for each factor.

A value was also assigned to reflect the quality of the data used to score the different factors based on the information available: (2) 
limited data, (1) expert judgment, or (0) no data available; following Hare et al. (2016). All scores were normalized and scaled from 0 to 1 (Table 3). The confidence level for sensitivity and exposure factors was calculated similarly. The confidence level of vulnerability results was calculated as the average of sensitivity and exposure confidence results, in percentage. Knowledge gaps, in sensitivity and exposure factors were identified based on the lowest confidence levels.

Hare et al. (2016) identified four steps in the climate vulnerability assessment process. The first three steps (step one: Scoping and Planning; step two: Assessment Preparation; step three: scoring) were applied identically in this study. In the analysis (fourth step) the calculations used for estimation of sensitivity, exposure, overall vulnerability and the confidence assessment differed from Hare et al. (2016) considering these metrics can only be applied with additional number of experts (see case study details below).

\section{Application to the case study}

This method was applied to the cetaceans in the Madeira archipelago. The archipelago is located in the Northeast Atlantic and is composed by two main islands and two sub-archipelagos: Madeira and Porto Santo, and Desertas and Selvagens, respectively (Fig. 1). The Economic Exclusive Zone (EEZ) of this archipelago comprises $446108 \mathrm{~km}^{2}$. There are 26 confirmed cetacean species in the Madeira archipelago (Ferreira et al., 2017; Freitas et al., 2012), out of approximately 90 known species (Jefferson et al., 2015), which makes Madeira a location with a high cetacean diversity.

The index factors were scored based on expert knowledge; in this case, two experts on Madeira's cetaceans (F. Alves and A. Dinis) were consulted and jointly evaluated each species and scored each factor resulting in a single assessment per species. When experts disagreed in the score attribution, an average between both scores was obtained.

Experts selected a group of species to apply the vulnerability index based on their Regional International Union for the Conservation of Nature (IUCN) Red List status (Freitas, 2004). From the twelve species for which a conservation status was attributed, six were evaluated as data deficient (DD) and therefore were not considered in this study. The remaining six species evaluated in this study were: the fin whale $(\mathrm{Ba}-$ laenoptera physalus) classified as Endangered (EN), sperm whale (Physeter macrocephalus) classified as Vulnerable (VU), and short-finned pilot whale (Globicephala macrorhynchus), Atlantic spotted dolphin (Stenella frontalis), common bottlenose dolphin (Tursiops truncatus) (hearafter just bottlenose dolphin) and short-beaked common dolphin

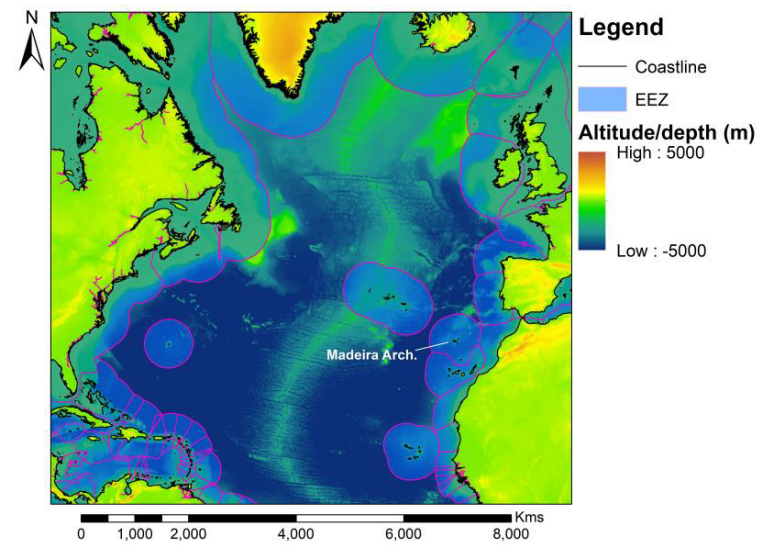

Fig. 1. Map of the North Atlantic ocean and the Madeira archipelago and Economic Exclusive Zone. Data source: EEZ: Flanders Marine Institute (2018); Coastline: Portuguese Hydrographic Institute (2014); Altitude and Depth: ETOPO2 dataset (National Geophysical Data Center, 2006).
(Delphinus delphis) classified as Least Concern (LC). Additionally, Bryde's whale (Balaenoptera brydei) was included in the list of target species in the present study given that, despite not being evaluated in Freitas (2004) (because it only started being recorded in Madeira in 2003; Freitas et al., 2012), it has been identified among the four most frequently sighted species in Madeira since 2005 (Alves et al., 2010, 2018b). Altogether, the seven target species considered in this study comprise over $88 \%$ of all cetacean sightings occurred in Madeira between 2005 and 2015 (Alves et al., 2018b).

In addition to the migratory populations, bottlenose dolphins and short-finned pilot whale have island-associated individuals using Madeiran waters on a regular basis (i.e. resident and/or temporary migrants) (Alves et al., 2013, 2018b; Dinis et al., 2016a, 2017), and therefore were analyzed as independent populations.

\section{Results}

\subsection{Index development}

The selection of sensitivity factors for the cetacean climate change vulnerability index showed that only two were overlapping: the maximum rate of population increase and the reproductive rate, as they measure related aspects of population dynamics (Table 1). Since data availability for both factors was very limited, they were not included the index. Other excluded factors presented lack of available data, such as life-history related factors (e.g. reproductive rate), ecological factors (e.g. site fidelity) and factors related to changes of environmental conditions (e.g. environmental tolerances, phenological cues, changes in trophic web) and their direct impact on species and ecosystems. Overall, this evaluation excluded eight factors and added seven factors to the index: population size, geographic distribution, diet diversity, migrations, human activities, genetic variability and IUCN status (Table 1).

For each of the seven selected factors, three vulnerability categories were established according to the previously defined methodology and with the support of the two local cetacean experts (Table 2).

Three sensitivity factors - genetic variability, diet and human activities, proved challenging to evaluate and categorize. Genetic variability is difficult to define due to the necessary selection of genetic indicators to be applied to a wide range of species. Since there are several measures of genetic variability there is not a specific indicator or threshold to distinguish among categories. Thus, this study followed the approach used by Young et al. (2011) for terrestrial species where the factor is scored qualitatively as a measure of relative variability in comparison to the genetic variability measured in related species. The diet factor categories were distinguished by one, more than two or three varieties of prey comprising $>20 \%$ of a species diet (Table 2 ).

\subsection{Index application to the case study}

The results of the experts' assessment are shown in Table 3. The scoring reflected species' specificities; for example, in the geographic distribution factor, scorings for the island-associated species reflected the larger degree of site fidelity in these species for the Madeira archipelago. It should be noted that information on the percentage of main prey type consumed by a species was often not available, and experts had to use an estimate to score the diet factor.

Exposure factors were evaluated considering the spatial distribution of each factors' anomalies in the North Atlantic. Experts attributed the same score to all exposure factors for each species since the latitudinal variation was the same. This was essentially attributed to the distribution range of species, i.e. species which migrate to the Arctic are more exposed since they experience a broad range of variation as opposed to island-associated species for which variation in exposure factors is small.

The experts' evaluation of both sensitivity and exposure factors 


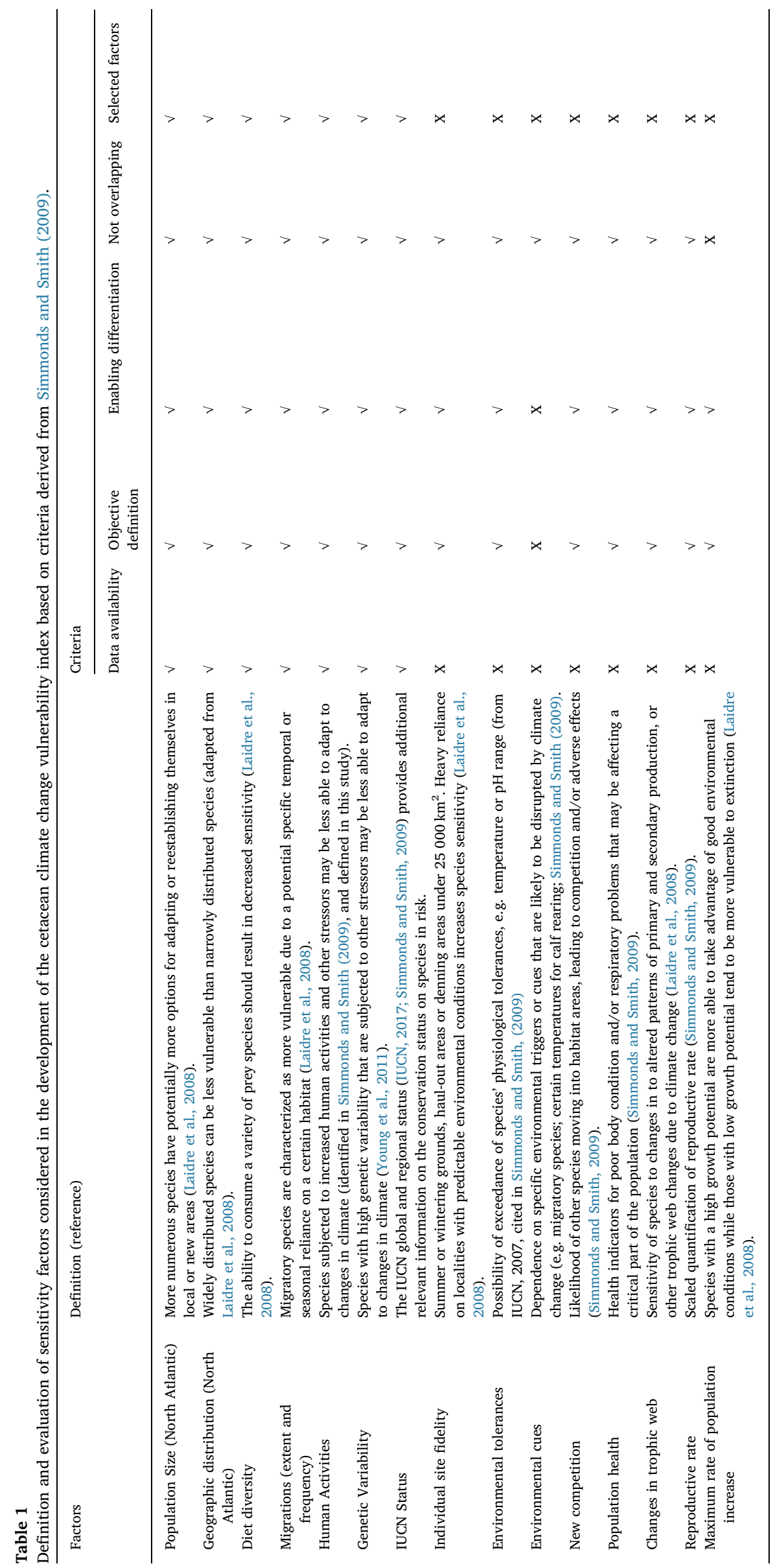


Table 2

Sensitivity categories defined for each sensitivity factors in the vulnerability index with three scores ranging from $1=$ the factor does not increase the species' sensitivity, to $3=$ the factor strongly increases species' sensitivity.

\begin{tabular}{|c|c|c|}
\hline Sensitivity factors & Category - scores (1 to 3 ) & References \\
\hline Population size & $\begin{array}{l}<100.000-\mathrm{SCORE}=3 \\
100.000-500.000-\mathrm{SCORE}=2 \\
>500.000-\mathrm{SCORE}=1\end{array}$ & Laidre et al., 2008 \\
\hline Geographic distribution & $\begin{array}{l}\text { restricted to a specific area }-\mathrm{SCORE}=3 \\
\text { widespread in the Northeast Atlantic but restricted by habitat (e.g. coastal or inshore waters) - } \\
\mathrm{SCORE}=2 \\
\text { widespread in the Northeast Atlantic }-\mathrm{SCORE}=1\end{array}$ & Defined by experts in this study \\
\hline Diet diversity & $\begin{array}{l}\text { One prey type comprises }>20 \% \text { of its diet }- \text { SCORE }=3 \\
\text { Two prey types comprise }>20 \% \text { of its diet }- \text { SCORE }=2 \\
\text { Three or more prey types comprise }>20 \% \text { of its diet }- \text { SCORE }=1\end{array}$ & Laidre et al., 2008 \\
\hline Migrations & $\begin{array}{l}\text { Whole population undertakes an annual migration of }>1000 \mathrm{~km} \text { along defined routes and specific } \\
\text { sites used through the year }-\mathrm{SCORE}=3 \\
\text { Population undertakes smaller migrations or substantial regional shifts }-\mathrm{SCORE}=2 \\
\text { Population stays in the same general region throughout the year }-\mathrm{SCORE}=1\end{array}$ & Laidre et al., 2008 \\
\hline Human activities & $\begin{array}{l}\text { Human activities contribute to an increase in species vulnerability }-\mathrm{SCORE}=3 \\
\text { Human activities do not increase nor decrease species vulnerability }-\mathrm{SCORE}=2 \\
\text { Human activities contribute to a decrease in species vulnerability }-\mathrm{SCORE}=1\end{array}$ & Defined by experts, in this study \\
\hline Genetic variability & $\begin{array}{l}\text { Low genetic variability compared to other evaluated cetacean species }- \text { SCORE }=3 \\
\text { Medium genetic variability compared to other evaluated cetacean species }- \text { SCORE }=2 \\
\text { High genetic variability compared to other cetacean species }- \text { SCORE }=1\end{array}$ & In this study \\
\hline IUCN Status & $\begin{array}{l}\text { Critically Endangered (CR), Endangered (EN) or Vulnerable }(\mathrm{VU})-\mathrm{SCORE}=3 \\
\text { Near Threatened }(\mathrm{NT})-\mathrm{SCORE}=2 \\
\text { Least Concern (LC) }-\mathrm{SCORE}=1\end{array}$ & $\begin{array}{l}\text { Defined by IUCN. Categories defined by experts } \\
\text { in this study }\end{array}$ \\
\hline
\end{tabular}

resulted in a ranking of cetacean species vulnerability to climate change (Table 3). The sensitivity factors that contributed most to species vulnerability were (small) population size, (impact of) human activities, and migration patterns. Confidence levels are lower for human activities factor since there is little evidence to support how these activities will evolve in the future. Species with the highest exposure scores were fin whales, bottlenose dolphins and common dolphins. Island-associated individuals had a lower exposure factor due to their site fidelity patterns in Madeira.

Data quality for sensitivity factors was higher for bottlenose dolphin (both oceanic and island-associated individuals), short-beaked common dolphins and island-associated short-finned pilot whales. The lowest result was attributed to Bryde's whales. These results reflect the available information for these species. Data quality for all exposure factors was considered equally adequate based on the source of the information provider - the NOAA's Climate Change Web Portal.

The most vulnerable species were sperm and fin whales and the least vulnerable species were the short-beaked common dolphin, together with the island-associated individuals of bottlenose dolphin and Atlantic spotted dolphins (Table 3). In the vulnerability assessment, the confidence levels were higher for island associated bottlenose dolphins (81\%) with all other species having a higher than $70 \%$ confidence level, except for sperm whale (69\%). It should be noted that confidence calculations differ from Hare et al. (2016), since in this study the two experts performed a single joint assessment and agreed in the scoring of data quality and distribution of tallies, with the exception of the IUCN status for the sperm whale (in which case an average was calculated).

\section{Discussion}

\subsection{Cetaceans' vulnerability to climate change in the Madeira archipelago}

This study shows that the index that we developed and trialled appears to function well in the assessment of species vulnerability to climate change. The index identifies and weighs relevant sensitivity and exposure factors providing a ranking of species vulnerability. The index proved useful in a context where limited information on observed and projected impacts of climate change for cetaceans in Madeira is available. Furthermore, most of the evidence on impacts of climate change derives from studies in species distribution changes. These studies provide information on geographic distribution, migration patterns and diet and show highly scored confidence levels. Other factors that require further research are human activities and their additional consequences on species vulnerability to climate change.

Of the seven cetacean species analyzed in this study, the vulnerability score identified the sperm whale as the most vulnerable, with a score of 0.52 . This is due to high scores in both sensitivity factors $(0.65$, the highest score) and exposure factors ( 0.8 , the highest score attributed to other two species: the fin whale and the bottlenose dolphin). The high sensitivity is due mostly to the low genetic variability and diet diversity, as well as one of the highest IUCN status and the highest migration score.

The second most vulnerable species is the fin whale, with a vulnerability score of 0.50 . This value is markedly close to the vulnerability score obtained for the sperm whale. In fact, the sensitivity scores of both species are very similar ( 0.6 and 0.65 respectively) due to their ecological similarities, although the genetic variability of sperm whales is considerably lower according to ocean-wide genetic studies (Lyrholm et al., 1999). In addition, exposure factors were scored similarly for both species despite the difference in male and female migratory patterns of sperm whales. While males are known to migrate to polar areas in the summer, females and calves distribute in tropical and subtropical areas. In Madeira, sperm whales are present throughout the year, mainly by groups of females and immatures (Freitas et al., 2012). However, even if females and calves are less exposed since they have more restricted distribution areas, males are essential to the population survival and overall vulnerability.

The highest IUCN score is attributed to fin whales. Considering the importance of the IUCN ranking in this assessment, we note that if the fin whale were to lose its endangered status to a lower status, the vulnerability score would decrease by 0,5 ( 0.45 vulnerability score) and 1 (0.39 vulnerability score) for Near Threatened and Least Concern, respectively. Despite not affecting the overall ranking, this may not be the case if IUCN status changes in conjunction with other factors. For diet diversity, the high sensitivity is due to North Atlantic fin whales consuming pelagic schooling fishes but mostly crustaceans such as northern krill Meganyctiphanes norvegica (Ryan et al., 2013). As for the migratory patterns of fin whales, they follow the generally accepted model of baleen whale migration worldwide, which describes seasonal movements from feeding grounds (high latitudes) and breeding grounds 


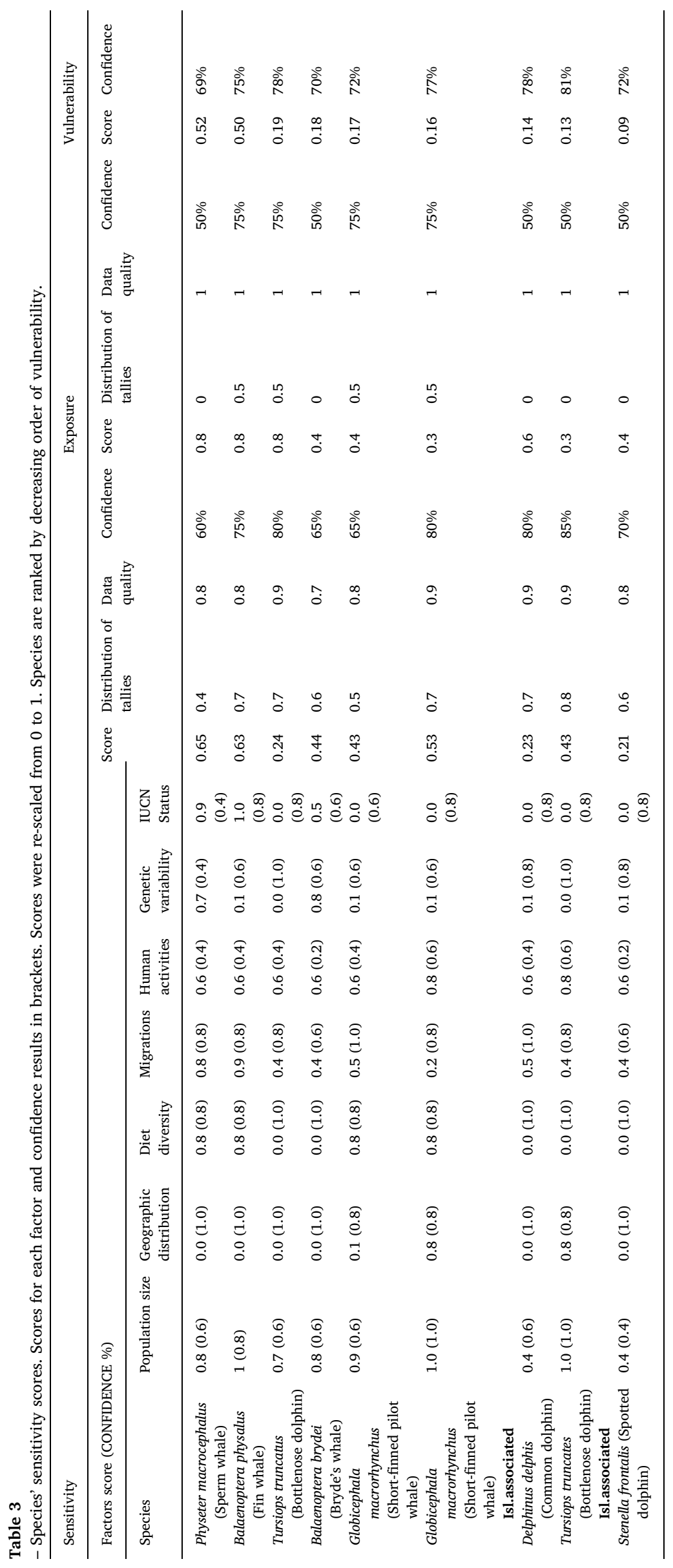


(low latitudes). Wide-ranging migratory species such as fin whales are more vulnerable to effects of climate change (Gauffier et al., 2018), leading to a higher score in the migration factor. In the nearby Azores archipelago (central North Atlantic), Silva et al. (2013) suggest that along their migratory route, fin whales alternate between periods of active migration and periods of area restricted habitat use. In Madeira, this species is observed with higher incidence in spring and summer (Freitas, 2004), suggesting that Madeira could also be a stopover area along their migratory route. Therefore, this species experiences more variations in exposure factors when compared with other species.

The next species in the vulnerability rank are the bottlenose dolphin and the Bryde's whale, with a vulnerability score of 0.19 and 0.18 , respectively. In this case it is worth noting that, although the overall vulnerability score is similar, there is a marked difference in the contribution of sensitivity factors and exposure factors for each species vulnerability score. The sensitivity score for the Bryde's whale $(0.44)$ is twice that of the bottlenose dolphin (0.24) due to two factors: i) genetic variability which was assumed low for Bryde's whale based on the available evidence for the Gulf of Mexico (Rosel and Wilcox, 2014), and ii) the IUCN category which was scored higher based on expert judgment. Bryde's whales are the least known of the large baleen whales and knowledge on their taxonomy, distribution and abundance is limited (Kato and Perrin, 2018). Their global IUCN status is Data Deficient, and their regional status was not attributed due to the limited information and their limited presence in the waters of Madeira (Freitas, 2004). However, since 2003 when they were first sighted in Madeira (Freitas et al., 2012), some individuals have demonstrated a seasonal residence during the summer (Alves et al., 2010). In contrast, the difference in the exposure factors score is of the same magnitude, except that it is higher for the bottlenose dolphin (0.8) than for the Bryde's whale (0.4). Bottlenose dolphins have a wider distribution range including in oceanic and coastal areas in the North Atlantic and are subject to higher variation in exposure factors while Bryde's whales have their northern limit distribution range around Madeira archipelago.

The following species in the vulnerability score rank is the Atlantic population and the island-associated individuals of short-finned pilot whales. The main difference in sensitivity factors $(0.43$ and 0.53 , respectively) is due to the high sensitivity score in the population size, geographic distribution and impact of human activities factors for the island-associated individuals. These individuals demonstrate a large degree of variability in site fidelity with an estimate 140 (95\% CI: 131-151) individuals using the southern and eastern waters of Madeira (Alves et al., 2015). Thus, the low vulnerability score is mostly due to a low exposure factor score (0.3), in fact, lower than the score attributed to all other species in this study due to their island-associated patterns of occurrence in Madeira.

The least vulnerable species are the common dolphin, the islandassociated bottlenose dolphins and the spotted dolphin, with vulnerability scores of $0.14,0.13$ and 0.09 respectively. The common dolphin and spotted dolphin show similar sensitivity scores for all contributing factors, and the difference in vulnerability scores was mostly due to different scores in exposure factors ( 0.6 and 0.4 , respectively). This scoring is due to common dolphins' distribution being further north than spotted dolphins which increases their exposure to climate factors.

Similarly to island-associated short-finned pilot whales, bottlenose dolphins in Madeira show large variability in residency pattern, with resident, transient and migrant individuals. Dinis et al. (2016b) found that, of the 400 dolphins found in southern Madeira, approximately $45.8 \%$ were resident dolphins. The island-associated individuals are less exposed to changes in climate factors and the main difference in sensitivity factors scoring is due to the diet of short-finned pilot whales consisting primarily of squid (Desportes and Mouritsen, 1993; Mintzer et al., 2008).

The confidence levels reflect the amount and accuracy of the information used to score each species in this study. Confidence levels are higher for island-associated species where most research studies take place. In Madeira, dolphin species have been probably more studied than baleen whales (Freitas et al., 2012; reviewed in Alves et al., 2018a), which is reflected in the confidence levels of sensitivity factors. Total confidence levels (i.e. vulnerability confidence levels) are high for all species due to the confidence attributed to exposure factors being $50 \%$ or higher; the weight of the sensitivity confidence scores have a lower contribution to total confidence levels. Comparing confidence levels readily informs which species and factors have greater knowledge gaps, which can provide an indication of where research efforts are necessary.

\subsection{Supporting evidence of climate change impacts in cetacean species}

Cetaceans' direct responses to climate change are difficult to discern due to other confounding factors such as the ones originated by anthropogenic activities. Nonetheless, several studies have gathered evidence of the impact of climate change leading to several modifications in cetacean species such as: distribution changes (e.g. Lambert et al., 2014), changes in timing and length of migrations (e.g. Ramp et al., 2015), lower conception rate and changes in community composition and structure (e.g. MacLeod et al., 2005). For some of the species accessed in this study, evidence of the impact of climate change has been described (see below), mostly related to changes in distribution patterns, which corroborates with the results of the vulnerability index for these factors. This shows that in fact the most relevant factors scored in the index are the ones for which some evidence has been observed.

For fin whales in the Mediterranean, Azzellino et al. (2008) found that a change in sea surface temperature led to a change in the species' distribution patterns. Nøttestad et al. (2015) also found changes in the distribution of baleen whales in the Norwegian Sea, namely minke whales (Balaenoptera acutorostrata) and fin whales (Balaenoptera physalus) due to changes in prey species. In particular, it is suggested that elevated sub-surface temperatures may be driving changes in the distribution and aggregation of macro-zooplankton which is becoming less available leading to a distribution overlap with pelagic fish which is becoming a more abundant dominant prey.

Ramp et al. (2015) found temporal and spatial changes in migration patterns of North Atlantic fin whales related to rising sea surface temperature and earlier ice break-up. This agrees with the index scoring of migration patterns and exposure factors for this species.

Sperm whales in the Mediterranean were also found to change their distribution patterns with changes in sea surface temperature, similarly to fin whales (Azzellino et al., 2008). In the Atlantic, rises in sea surface temperature led to changes in movement patterns of sperm whales, probably related to changes in squid prey species distribution. This was reported by Pierce et al. (2007) in the North Sea resulting in an increase in strandings and by Robinson et al. (2005) in the Northeast Atlantic where shifts in the North Atlantic Oscillation could affect squid prey species. The high scoring of migration and diet together with exposure factors for sperm whales supports the index results. In addition, in the Galapagos, periods of warmer sea water (usually caused by El Niño events) have been associated with a decrease in reproductive success of sperm whales (Whitehead, 1997). For short-finned pilot whales, increasing sea surface temperatures in the North Atlantic may cause a northward range shift, which may lead to interspecies hybridization with the long-finned pilot whale (Globicephala melas) (Miralles et al., 2016).

Kerosky et al. (2012) found an increase in Bryde's whales detected calls in the Southern California Bight between 2000 and 2010, indicating a potential seasonal range expansion. The authors suggest that these individuals may be following prey outside their boundary distribution range and may therefore be affected by long-term climate variability. For bottlenose dolphins a number of studies have related changes caused by climate change. In the Mediterranean, bottlenose dolphin populations were found to spend more time and effort in 
feeding activities due to reduced prey availability (Politi, 1998; Bearzi and Politi, 1999). Lusseau et al. (2004) reported that group sizes of bottlenose dolphins in Moray Firth (UK) varied from year to year in relation to large scale ocean climate variation; since local indices of prey abundance vary with climate and availability of prey affect predator group sizes, changes in social organization of cetaceans' population occur, as they tend to live in smaller groups when there were less salmon. Also, in the Northeast coast of Scotland, Wilson et al. (2004) found evidence of a recent range expansion beyond the bottlenose dolphins' northern limit that may be related to changes in prey abundance and/or distribution generated by climate variation. Finally, the alteration of the distribution and availability of key prey species in the Adriatic Sea, possibly due to climatic shifts led to a change in distribution patterns of bottlenose dolphin populations (Blanco et al., 2001).

Common dolphins in Northwest Scotland have been shown to have expanded their range in a poleward shift, altering the species' distribution (MacLeod et al., 2005). Similarly, to bottlenose dolphins, changes in distribution and availability of prey species in the Adriatic Sea attributable to climate change led to a change in distribution patterns of common dolphin populations (Blanco et al., 2001). Finally, in the Alboran Sea, a potential reduction in common dolphins' suitable habitat may occur due to an increase in sea surface temperature (Cañadas and Vázquez, 2017).

In Madeira, few studies have been conducted on the observed impacts of climate change on marine species. These show that non-indigenous fish in marine waters of Madeira were found to be range expansions from tropical and subtropical areas that are extending their northern limit, possibly due to climate change (Freitas and CanningClode, 2014). The arrival and increase in tropical fish species such as Abudefduf saxatilis, Aluterus scriptus, Canthidermis sufflamen, Caranx crysos and Gnatholepis thompsoni may lead to a significant change in the faunal composition of Madeira (Bianchi et al., 1999; Wirtz et al., 2008; Freitas and Canning-Clode, 2014).

In Madeira there are limited observations of changes in cetacean species potentially attributed to climate change. It is suggested that island-associated individuals of short-finned pilot whales and bottlenose dolphins rely on the archipelago's oceanographic features for feeding and breeding (Alves et al., 2015; Dinis et al., 2017), which may differ under climate change. Moreover, tropical species such as the Bryde's whale and the Atlantic spotted dolphin have been recorded in Madeira only in 1997 and 2003, respectively (Freitas et al., 1998, 2012), and nowadays are among the most four frequently sighted cetacean species (Alves et al., 2018a). A similar explanation to that of the Southern California Bight (Kerosky et al., 2012) can be proposed to explain that scenario, i.e. an increase in temperature is altering the northern limit of distribution of several fish species, which may have resulted in an increase in the number of Bryde's whales in the area.

\subsection{Case study contributions to cetaceans' vulnerability assessment}

The limited availability of ecological information on cetacean species and evidence of the observed impacts of climate change, as described above, creates a challenge when attempting to predict changes in cetacean species due to climate change. The index developed in this study can assist in the prioritization of species vulnerability, which makes it a useful tool for decision-makers prioritizing conservation and adaptation measures for cetaceans under climate change. This usefulness can be expanded, since marine mammals, namely cetacean species, have been considered prime sentinel species of ecosystem health (Moore, 2008; Bossart, 2011). These species are top predators with long life spans and thus provide indications of changes in marine ecosystems.

From an economic standpoint these populations are also particularly relevant for tourism and are a key economic activity, particularly in insular ecosystems. This accentuates the necessity to preserve cetacean species with informed, science-based policies. In Madeira, the most recent estimates (O'Connor et al., 2009) indicate that the Archipelago grew its whale watching activity by $73 \%$ between 1998 and 2008 as it became an essential part of the archipelagos' proceeds. It accounts for 7\% of Europe's whale watchers and together with Azores islands has the largest portion for Europe with approximately $23 \%$ of total revenues (O'Connor et al., 2009). This makes the vulnerability assessment of cetacean species an important part of a larger socioeconomic vulnerability assessment in Madeira and similar archipelagos.

The implications of climate change for species management are challenging to address due to lack of information and baseline data on cetacean populations. The collection of long-term data through monitoring schemes are essential to provide robust evidence on population changes that can promote modeling advances in the projection of species distribution under climate change (Simmonds, 2016; Silber et al., 2017). Concrete management actions generally focus on the reduction of existing human pressures on populations or on flexible approaches in the management of marine protected areas. In Madeira, the main threat to cetacean populations are the interactions with the whale watching boats and maritime traffic (Cunha, 2013, SRA, 2014). The interactions of cetaceans with fishing vessels are reduced and there are only a few records of by-catch (Nicolau et al., 2014). In 2016, a site for the protection of cetacean species was created by the regional government with a total area of 681,980 ha to protect the critical habitat areas for bottlenose dolphins and other cetacean species as well as the loggerhead turtle (Caretta caretta) and the mediterranean monk seal (Monachus monachus). The site is currently under assessment for approval by the European Commission to integrate the Natura 2000 network. In the future the assessment of species vulnerability to climate change should be integrated in the development of adequate conservation actions for the Madeira archipelago.

This study is a first attempt at the use of trait-based indices to assess the vulnerability cetacean species to climate change in this region. The method used includes the integration of sensitivity and exposure factors and provides a more holistic approach and, consequently, a more accurate grading of each species' vulnerability. The detailed specification of factors, such as human activities, can be improved in the future to provide a better assessment of impacts in a particular population or study area. The method can be adapted as needed and applied to other species and locations.

This is also an exploratory study and while the results can be useful as preliminary information to scientists and policy makers it can and should be expanded upon as more information is obtained. The structure of this study allows data input to be improved upon. More information can be added when available and the inclusion of experts as needed for each study to provide more reliable results is also possible. In the future we aim to include additional experts and extend the vulnerability assessment to the Macaronesia region which would increase our expert pool and allow for the discuss the management implications at a broader scale.

Species and factors that need more data are readily identifiable with the evaluation of confidence levels. For example, human activities, population size or genetic diversity are a few of the factors with low confidence levels. These reflect the amount and accuracy of the data, with lower confidence levels indicating substantial knowledge gaps.

\section{Conclusion}

This study developed a trait-based index to assess the vulnerability of cetacean species to climate change. Different methods for vulnerability assessment have been developed in recent years and continue to be improved, particularly for the marine environment. This exploratory study presents a contribution to this effort. The most vulnerable species are fin and sperm whale, bottlenose dolphin and Bryde's whale. The main factors determining differences between species are diet diversity, migrations, IUCN status and exposure. Other factors may be more 
relevant for other species in other areas. In general confidence levels are high but some factors such as the degree to which human activities may influence species vulnerability to climate change should be further investigated.

The challenges and limitations associated with this index were addressed where possible. In the future, however, new information on species ecology can be used to update the index and obtain a more comprehensive ranking of vulnerability for the species found in Madeira.

A broader use of the index will allow its further development and improvement. It can be used as a foundation for the development of other indexes in other locations and with other species. In addition, integrative and new approaches for assessing the vulnerability of species to climate change will continue to be developed and improved and will contribute to the evolution of the method presented in this study. This method can be used together with distribution models or scenariobased approaches, complementing the information they present.

\section{Acknowledgments}

This study was supported by the CLIMA-MADEIRA project and authors would like to thank Hugo Costa and Pedro Garrett for their support during this work as well as Andreia Pereira and Francisco Martinho for initial feedback on the vulnerability index. The work of A. Sousa, J.P. Nunes and J. Bentz, was supported by the Fundação para a Ciência e a Tecnologia (grant refs. PD/BD/135352/2017, IF/00586/2015 and SFRH/BPD/115656/2016) co-funded by the European Social Fund. A. Sousa would like to thank Ana Jerónimo for the substantial support, as well as the comprehensive and valuable comments to the work. This study was partially supported by the Oceanic Observatory of Madeira throughout the project M1420-01-0145-FEDER-000001-OOM. F. Alves and A. Dinis acknowledge ARDITI - Madeira's Regional Agency for the Development of Research, Technology and Innovation, for funding their research throughout the Project Madeira M1420-09-5369-FSE-000001.

\section{Appendix A. Supplementary data}

Supplementary data to this article can be found online at https:// doi.org/10.1016/j.ecolind.2018.10.046.

\section{References}

Aguilar, A., Raga, J., 1993. The striped dolphin Epizootic in the Mediterranean Sea. Ambio 22, 524-528.

Alves, F., Dinis, A., Cascão, I., Freitas, L., 2010. Bryde's whale (Balaenoptera brydei) stable associations and dive profiles: new insights into foraging behavior. Mar. Mammal Sci. 26, 202-212. https://doi.org/10.1111/j.1748-7692.2009.00333.x.

Alves, F., Quérouil, S., Dinis, A., Nicolau, C., Ribeiro, C., Freitas, L., Kaufmann, M., Fortuna, C., 2013. Population structure of short-finned pilot whales in the oceanic archipelago of Madeira based on photo-identification and genetic analyses: implications for conservation. Aquat. Conserv. Mar. Freshw. Ecosyst. 23, 758-776. https://doi.org/10.1002/aqc.2332.

Alves, F., Alessandrini, A., Servidio, A., Mendonça, S.A., Hartman, K., Prieto, R., Berrow, S., Magalhães, S., Steiner, L., Santos, R., Ferreira, R., Pérez, M.J., Ritter, F., Dinis, A., Martín, V., Silva, M., Soto, N.A., 2018b. Complex biogeographical patterns support an ecological connectivity network of a large marine predator in the north-east Atlantic. Divers Distrib 1-16. https://doi.org/10.1111/ddi.12848.

Alves, F., Dinis, A., Nicolau, C., Ribeiro, C., Kaufmann, M., Fortuna, C., Freitas, L., 2015. Survival and abundance of short-finned pilot whales in the archipelago of Madeira, NE Atlantic. Mar. Mammal Sci. 31, 106-121. https://doi.org/10.1111/mms.12137.

Alves, F., Ferreira, R., Fernandes, M., Halicka, Z., Dias, L., Dinis, A., 2018a. Analysis of occurrence patterns and biological factors of cetaceans based on long-term and finescale data from platforms of opportunity: Madeira Island as a case study. Mar. Ecol., e12499. https://doi.org/10.1111/maec.12499.

Azzellino, A., Gaspari, S.A., Airoldi, S., Lanfredi, C., 2008. Biological consequences of global warming: does sea surface temperature affect cetacean distribution in the western Ligurian Sea? J. Mar. Biol. Assoc. U.K. 88, 1145-1152. https://doi.org/10. 1017/S0025315408000751.

Bagne, K.E., Friggens, M.M., Finch, D.M. 2011. A system for Assessing Vulnerability of Species (SAVS) to Climate Change. United States Department of Agriculture, Forest Service, Rocky Mountain Research Station.

Bearzi, G., Politi, E., 1999. Diurnal behavior of free-ranging bottlenose dolphins in the Kvarneric (Northern Adriatic Sea). Mar. Mammal Sci. 15, 1065-1097. https://doi. org/10.1111/j.1748-7692.1999.tb00878.x

Bianchi, C.N., Morri, C., Sartoni, G., Wirtz, P., 1999. Sublittoral epibenthic communities around Funchal (Island of Madeira, NE Atlantic): an update of previous information and a comparison with the Mediterranean Sea. Bol. Mus. Munic Funchal Sup. 5, $59-80$.

Blanco, C., Salomón, O., Raga, J.A., 2001. Diet of the bottlenose dolphin (Tursiops truncatus) in the western Mediterranean Sea. J. Mar. Biol. Assoc. U.K. 81, 1053-1058. https://doi.org/10.1017/S0025315401005057.

Bossart, G.D., 2011. Marine mammals as sentinel species for oceans and human health. Vet. Pathol. 48, 676-690. https://doi.org/10.1177/0300985810388525.

Brooker, R., Young, J.C., Watt, A.D., 2007. Climate change and biodiversity: impacts and policy development challenges-a European case study. Int. J. Biodivers. Sci. Manage. 3, 12-30.

Cañadas, A., Vázquez, J.A., 2017. Common dolphins in the Alboran Sea: $\mathrm{f}$ acing a reduction in their suitable habitat due to an increase in Sea surface temperature. Deep Sea Res. Part II Top. Stud. Oceanogr. 141, 306-318. https://doi.org/10.1016/J. DSR2.2017.03.006.

Cunha, I., 2013. Marine Traffic and Potential Impacts Towards Cetaceans within the Madeira EEZ: a Pioneer Study. MSc Thesis. University of Oporto, Portugal, pp. 140.

Cruz, M.J., Robert, E., Costa, T., Avelar, D., Rebelo, R., Pulquério, M., 2015. Assessing biodiversity vulnerability to climate change: testing different methodologies for Portuguese herpetofauna. Region. Environ. Change 16, 1293-1304. https://doi.org/ 10.1007/s10113-015-0858-2.

Davison, J.E., Coe, S., Finch, D., Rowland, E., Friggens, M., Graumlich, L.J., 2012 Bringing indices of species vulnerability to climate change into geographic space: an assessment across the Coronado national forest. Biodivers. Conserv. 21, 189-204. https://doi.org/10.1007/s10531-011-0175-0.

Desportes, G., Mouritsen, R., 1993. Preliminary results on the diet of long-finned pilot whales off the Faroe Islands. Report of the International Whaling Commission (Special Issue) 14, 305-324.

Dinis, A., Alves, F., Nicolau, C., Ribeiro, C., Kaufmann, M., Cañadas, A., Freitas, L., 2017. Social structure of a population of bottlenose dolphins (Tursiops truncatus) in the oceanic archipelago of Madeira, Portugal. J. Mar. Biol. Assoc. U.K. 1-9. https://doi. org $/ 10.1017 /$ S0025315417000650.

Dinis, A., Alves, F., Nicolau, C., Ribeiro, C., Kaufmann, M., Cañadas, A., Freitas, L., 2016a Bottlenose dolphin Tursiops truncatus group dynamics, site fidelity, residency and movement patterns in the Madeira Archipelago (North-East Atlantic). Afr. J. Mar. Sci. 38, 151-160. https://doi.org/10.2989/1814232X.2016.1167780.

Dinis, A., Carvalho, A., Alves, F., Nicolau, C., Ribeiro, C., Kaufmann, M., Cañadas, A., Freitas, L., 2016b. Spatial and temporal distribution of bottlenose dolphins, Tursiops truncatus, in the Madeira archipelago, NE Atlantic. Arquipel. - Life Mar. Sci. 33, 45-54.

Duarte, C.M., 2000. Marine biodiversity and ecosystem services: an elusive link. J. Exp. Mar. Biol. Ecol. 250, 117-131. https://doi.org/10.1016/S0022-0981(00)00194-5.

EEA, 2016. Climate change, impacts and vulnerability in Europe 2016 An indicator-based report, EEA Report No 1/2017. https://doi.org/10.2800/66071.

EEA, 2012. Climate change, impacts and vulnerability in Europe 2012: an indicator-based report, EEA Report. https://doi.org/10.2800/66071.

Ferreira, R., Alves, F., Gomes, C., Jardim, D., Kok, J., Dinis, A., 2017. First confirmed record of northern bottlenose whale Hyperoodon ampullatus in Madeira Archipelago, NE Atlantic. Aquat. Mammals 43, 474-478. https://doi.org/10.1578/AM.43.5.2017. 474.

Flanders Marine Institute, 2018. Maritime Boundaries Geodatabase: Maritime Boundaries and Exclusive Economic Zones (200NM), version 10. doi: 10.14284/312.

Freitas, C.M.A., Reiner, F., Dellinger, T., 1998. First record of Atlantic spotted dolphins, Stenella frontalis G. Cuvier, 1829 (Cetacea: Delphinidae) from the Archipelago of Madeira. Bocagiana 190, 1-5.

Freitas, L., 2004. Estatutos de conservação dos cetáceos no arquipélago da Madeira (documento F). Relatório técnico do Projecto CETACEOSMADEIRA (LIFE99 NAT/P/ 06432). Museu da Baleia da Madeira, Caniçal.

Freitas, L., Dinis, A., Nicolau, C., Ribeiro, C., Alves, F., 2012. New records of cetacean species for Madeira Archipelago with an updated checklist. Bol. Mus. Munic Funchal $62,25-43$

Freitas, M., Canning-Clode, J., 2014. Non-indigenous fish in the fresh and marine waters of the Madeira Archipelago, in: SIBIC2014 - V Jornadas Ibérica de Ictiologia. https:// doi.org/10.13140/2.1.4837.4560.

Gambaiani, D.D., Mayol, P., Isaac, S.J., Simmonds, M.P., 2009. Potential impacts of climate change and greenhouse gas emissions on Mediterranean marine ecosystems and cetaceans. J. Mar. Biol. Assoc. U.K. 89, 179-201. https://doi.org/10.1017/ S0025315408002476.

Gardali, T., Seavy, N.E., DiGaudio, R.T., Comrack, L.A., 2012. A climate change vulnerability assessment of california's at-risk birds. PLoS One 7, e29507. https://doi.org/ 10.1371/journal.pone.0029507.

Gauffier, P., Verborgh, P., Giménez, J., Esteban, R., Salazar Sierra, J., de Stephanis, R., 2018. Contemporary migration of fin whales through the Strait of Gibraltar. Mar. Ecol. Prog. Ser. 588, 215-228. https://doi.org/10.3354/meps12449.

Girvetz, E.H., Gray, E., Tear, T.H., Brown, M.A., 2014. Bridging climate science to adaptation action in data sparse Tanzania. Environ. Conserv. 41, 229-238. https:// doi.org/10.1017/S0376892914000010.

Hare, J.A., Morrison, W.E., Nelson, M.W., Stachura, M.M., Teeters, E.J., Griffis, R.B Alexander, M.A., Scott, J.D., Alade, L., Bell, R.J., Chute, A.S., Curti, K.L., Curtis, T.H., Kircheis, D., Kocik, J.F., Lucey, S.M., McCandless, C.T., Milke, L.M., Richardson, D.E., Robillard, E., Walsh, H.J., McManus, M.C., Marancik, K.E., Griswold, C.A., 2016. A vulnerability assessment of fish and invertebrates to climate change on the northeast u.s. continental shelf. PLoS One 11, 1-30. https://doi.org/10.1371/journal.pone. 0146756. 
Heller, N.E., Zavaleta, E.S., 2009. Biodiversity management in the face of climate change: a review of 22 years of recommendations. Biol. Conserv. 142, 14-32. https://doi.org/ 10.1016/J.BIOCON.2008.10.006.

Hoegh-Guldberg, O., Bruno, J.F., 2010. The impact of climate change on the world's marine ecosystems. Science 328, 1523-1528. https://doi.org/10.1126/science. 1189930.

IPCC, 2014. Summary for Policymakers, Climate Change 2014: Synthesis Report Contribution of Working Groups I, II and III to the Fifth Assessment Report of the Intergovernmental Panel on Climate Change. https://doi.org/10.1017/ СВО9781107415324.

IUCN, 2017. IUCN Red List of Threatened Species [WWW Document]. Version 2017.3. URL www.iucnredlist.org.

Jefferson, T.A., Webber, M.A., Pitman, R.L., Gorter, U., 2015. Marine Mammals of the World: A Comprehensive Guide to their Identification. Academic Press.

Kato, H., Perrin, W.F., 2018. Bryde's whale. In: Encyclopedia of Marine Mammals. Elsevier, pp. 143-145. https://doi.org/10.1016/B978-0-12-804327-1.00079-0.

Kerosky, S.M., Širović, A., Roche, L.K., Baumann-Pickering, S., Wiggins, S.M., Hildebrand, J.A., 2012. Bryde's whale seasonal range expansion and increasing presence in the Southern California Bight from 2000 to 2010. Deep Res. Part I Oceanogr. Res. Pap. 65, 125-132. https://doi.org/10.1016/j.dsr.2012.03.013.

Kovacs, K.M., Lydersen, C., 2008. Climate change impacts on seals and whales in the North Atlantic Arctic and adjacent shelf seas. Sci. Progr. 91 (2), 117-150. https://doi org/10.3184/003685008X324010.

Laidre, K.L., Stirling, I., Lowry, L.F., Wiig, Ø., Heide-Jørgensen, M.P., Ferguson, S.H., 2008. Quantifying the sensitivity of arctic marine mammals to climate-induced habitat change. Ecol. Appl. 18, 97-125. https://doi.org/10.1890/06-0546.1.

Lambert, E., Pierce, G.J., Hall, K., Brereton, T., Dunn, T.E., Wall, D., Jepson, P.D. Deaville, R., MacLeod, C.D., 2014. Cetacean range and climate in the eastern North Atlantic: future predictions and implications for conservation. Glob. Change Biol. 20, 1782-1793. https://doi.org/10.1111/gcb.12560.

Lankford, A.J., Svancara, L.K., Lawler, J.J., Vierling, K., 2014. Comparison of climate change vulnerability assessments for wildlife. Wildl. Soc. Bull. 38, 386-394. https:// doi.org/10.1002/wsb.399.

Leaper, R., Cooke, J., Trathan, P., Reid, K., Rowntree, V., Payne, R., 2006. Global climate drives southern right whale (Eubalaena australis) population dynamics. Biol. Lett. 2, 289-292. https://doi.org/10.1098/rsbl.2005.0431.

Learmonth, J.A., MacLeod, C.D., Santos, M.B., Pierce, G.J., Crick, H.Q.P., Robinson, R.A., 2006. Potential effects of climate change on marine mammals. Oceanogr. Mar. Biol. 44, 431-464.

Lusseau, D., Williams, R., Wilson, B., Grellier, K., Barton, T.R., Hammond, P.S., Thompson, P.M., 2004. Parallel influence of climate on the behaviour of Pacific killer whales and Atlantic bottlenose dolphins. Ecol. Lett. 7, 1068-1076. https://doi.org/ 10.1111/j.1461-0248.2004.00669.x.

Lyrholm, T., Leimar, O., Johanneson, B., Gyllensten, U., 1999. Sex-biased dispersal in sperm whales: contrasting mitochondrial and nuclear genetic structure of global populations. Proc. Biol. Sci. 266, 347-354. https://doi.org/10.1098/rspb.1999.0644.

MacLeod, C., 2009. Global climate change, range changes and potential implications for the conservation of marine cetaceans: a review and synthesis. Endanger. Species Res. 7, 125-136. https://doi.org/10.3354/esr00197.

MacLeod, C.D., Bannon, S.M., Pierce, G.J., Schweder, C., Learmonth, J.A., Herman, J.S., Reid, R.J., 2005. Climate change and the cetacean community of north-west Scotland. Biol. Conserv. 124, 477-483. https://doi.org/10.1016/J.BIOCON.2005.02. 004.

Millennium Ecosystem Assessment, 2005. In: Ecosystems and Human Well-being: Synthesis. Island Press, Washington, DC. https://doi.org/10.1196/annals.1439.003.

Mintzer, V.J., Gannon, D.P., Barros, N.B., Read, A.J., 2008. Stomach contents of mass stranded short-finned pilot whales (Globicephala macrorhynchus) from North Carolina. Mar. Mammal Sci. 24, 290-302.

Miralles, L., Oremus, M., Silva, M.A., Planes, S., Garcia-Vazquez, E., 2016. Interspecific hybridization in pilot whales and asymmetric genetic introgression in northern Globicephala melas under the scenario of global warming. PLoS One 11, e0160080. https://doi.org/10.1371/journal.pone.0160080.

Moore, S.E., 2008. Marine mammals as ecosystem sentinels. J. Mammal. 89, 534-540. https://doi.org/10.1644/07-MAMM-S-312R1.1.

National Geophysical Data Center, 2006. 2-minute Gridded Global Relief Data (ETOPO2) v2. National Geophysical Data Center, NOAA. doi:10.7289/V5J1012Q.

Nicolau, C., Alves, F., Freitas, L. 2014. Surveillance of the conservation status of cetaceans species in Madeira offshore waters. Technical report of the CETACEOSMADEIRA Project. Museu da Baleia da Madeira, Caniçal.

Nøttestad, L., Krafft, B.A., Anthonypillai, V., Bernasconi, M., Langård, L., Mørk, H.L. Fernö, A., 2015. Recent changes in distribution and relative abundance of cetaceans in the Norwegian Sea and their relationship with potential prey. Front. Ecol. Evol. 2,83 .

O'Connor, S., Campbell, R., Cortez, H., Knowles, T., 2009. Whale Watching Worldwide: tourism numbers, expenditures and expanding economic benefits, a special report from the International Fund for Animal Welfare. Yarmouth MA, USA, Prep. by Econ. Large 228.

Pacifici, M., Foden, W.B., Visconti, P., Watson, J.E.M., Butchart, S.H.M., Kovacs, K.M., Scheffers, B.R., Hole, D.G., Martin, T.G., Akçakaya, H.R., Corlett, R.T., Huntley, B., Bickford, D., Carr, J.A., Hoffmann, A.A., Midgley, G.F., Pearce-Kelly, P., Pearson, R.G., Williams, S.E., Willis, S.G., Young, B., Rondinini, C., 2015. Assessing species vulnerability to climate change. Nat. Clim. Change 5, 215-224.
Palumbi, S.R., Sandifer, P.A., Allan, J.D., Beck, M.W., Fautin, D.G., Fogarty, M.J., Halpern, B.S., Incze, L.S., Leong, J.-A., Norse, E., Stachowicz, J.J., Wall, D.H., 2009. Managing for ocean biodiversity to sustain marine ecosystem services. Front. Ecol. Environ. 7, 204-211. https://doi.org/10.1890/070135.

Pierce, G.J., Santos, M.B., Smeenk, C., Saveliev, A., Zuur, A.F., 2007. Historical trends in the incidence of strandings of sperm whales (Physeter macrocephalus) on North Sea coasts: an association with positive temperature anomalies. Fish. Res. 87, 219-228. https://doi.org/10.1016/J.FISHRES.2007.06.001.

Politi, E., 1998. Un progetto per i delfini in Mediterraneo. Le Sci. 360, 64-69.

Portuguese Hydrographic Institute, 2014. World Vector Shoreline/Linha de Costa do Mundo. Available online at http://www.hidrografico.pt/.

Ramp, C., Delarue, J., Palsbøll, P.J., Sears, R., Hammond, P.S., 2015. Adapting to a warmer ocean-seasonal shift of baleen whale movements over three decades. PLoS One 10, e0121374. https://doi.org/10.1371/journal.pone.0121374.

Robinson, R.A., Learmonth, J.A., Hutson, A.M., Macleod, C.D., Sparks, T.H., Leech, D.I., Pierce, G.J., Rehfisch, M.M., Crick, H.Q.P., 2005. Climate Change and Migratory Species. A Report for Defra Research Contract CR0302.

Rosel, P., Wilcox, L., 2014. Genetic evidence reveals a unique lineage of Bryde's whales in the northern Gulf of Mexico. Endanger. Species Res. 25, 19-34. https://doi.org/10. 3354/esr00606.

Ryan, C., McHugh, B., Trueman, C., Sabin, R., Deaville, R., Harrod, C., Berrow, S., O'Connor, I., 2013. Stable isotope analysis of baleen reveals resource partitioning among sympatric rorquals and population structure in fin whales. Mar. Ecol. Prog. Ser. 479, 251-261. https://doi.org/10.3354/meps10231.

Salomon, M., Dahms, H., 2018. Marine ecosystem services. In: Handbook on Marin Environment Protection. Springer International Publishing, Cham, pp. 67-75. https://doi.org/10.1007/978-3-319-60156-4_3.

Silber, G.K., Lettrich, M.D., Thomas, P.O., Baker, J.D., Baumgartner, M., Becker, E.A., Boveng, P., Dick, D.M., Fiechter, J., Forcada, J., Forney, K.A., Griffis, R.B., Hare, J.A. Hobday, A.J., Howell, D., Laidre, K.L., Mantua, N., Quakenbush, L., Santora, J.A. Stafford, K.M., Spencer, P., Stock, C., Sydeman, W., Van Houtan, K., Waples, R.S. 2017. Projecting marine mammal distribution in a changing climate. Front. Mar. Sci. 413. https://doi.org/10.3389/fmars.2017.00413.

Silva, M.A., Prieto, R., Jonsen, I., Baumgartner, M.F., Santos, R.S., 2013. North Atlantic blue and fin whales suspend their spring migration to forage in middle latitudes: building up energy reserves for the journey? PLoS One 8, e76507. https://doi.org/10. 1371/journal.pone.0076507.

Simmonds, M.P., Eliott, W.J., 2009. Climate change and cetaceans: concerns and recent developments. J. Mar. Biol. Assoc. U.K. 89, 203-210. https://doi.org/10.1017/ S0025315408003196.

Simmonds, M.P., Isaac, S.J., 2007. The impacts of climate change on marine mammals: early signs of significant problems. Oryx 41, 19-26. https://doi.org/10.1017/ S0030605307001524.

Simmonds, M.P., Mayer, S.J., 1997. An evaluation of environmental and other factors in some recent marine mammal mortalities in Europe: implications for conservation and management. Environ. Rev. 5, 89-98. https://doi.org/10.1139/a97-004.

Simmonds, M.P., Smith, V., 2009. Cetaceans and Climate Change - Assessing the Risks. Rep. Paper submitted to the Scientific Committee of the International Whaling Commission SC-F09-CC8 25 pages.

Simmonds, M.P., 2016. Impacts and effects of ocean warming on marine mammals. Ful report In: Laffoley, D., Baxter, J.M. (Eds.), Explaining Ocean Warming: Causes, Scale, Effects and Consequences. IUCN, Gland, Switzerland, pp. 303-320.

SRA., 2014. Marine Strategy for Madeira subdivision. Marine Strategy Framework Directive (MSFD). Regional Secretariat of Environment and Natural Resources. June 2014

Stortini, C.H., Shackell, N.L., Tyedmers, P., Beazley, K., 2015. Assessing marine species vulnerability to projected warming on the Scotian Shelf, Canada. ICES. J. Mar. Sci. J. du Cons. 72, 1731-1743. https://doi.org/10.1093/icesjms/fsv022.

Whitehead, H., 1997. Sea surface temperature and the abundance of sperm whale calves off the Galapagos Islands: implications for the effects of global warming. Rep. Int Whal. Comm. 47, 941-944.

Whitehead, H., McGill, B., Worm, B., 2008. Diversity of deep-water cetaceans in relation to temperature: implications for ocean warming. Ecol. Lett. 11, 1198-1207. https:// doi.org/10.1111/j.1461-0248.2008.01234.x.

Wilson, B., Reid, R.J., Grellier, K., Thompson, P.M., Hammond, P.S., 2004. Considering the temporal when managing the spatial: a population range expansion impacts protected areas-based management for bottlenose dolphins. Anim. Conserv. 7, 331-338. https://doi.org/10.1017/S1367943004001581.

Wirtz, P., Fricke, R., Biscoito, M., 2008. The coastal fishes of Madeira Island - new records and an annotated check-list. Zootaxa 1715, 1-26.

Worm, B., Barbier, E.B., Beaumont, N., Duffy, J.E., Folke, C., Halpern, B.S., Jackson, J.B.C., Lotze, H.K., Micheli, F., Stephen, R., Sala, E., Selkoe, K., Stachowicz, J.J., Watson, R., Worm, B., Folke, C., Watson, R., Barbier, B., Emmett, J., Halpern, S. Micheli, F., Palumbi, S.R., Sala, E., Selkoe, K., 2006. Impacts of biodiversity loss on ocean ecosystem services. Science $314,787-790$.

Young, B., Byers, E., Gravuer, K., Hall, K., Hammerson, G., Redder, A., 2011. Guidelines for Using the NatureServe Climate Change Vulnerability Index. NatureServe, Arlington, Virginia, USA.

Young, B.E., Dubois, N.S., Rowland, E.L., 2015. Using the climate change vulnerability index to inform adaptation planning: lessons, innovations, and next steps. Wildl. Soc. Bull. 39, 174-181. https://doi.org/10.1002/wsb.478. 